UDC 538.4

\title{
To Evaluation Test of Quality of Magnetic Fluids for Magnetofluid Devices
}

\author{
V. G. Bashtovoi ${ }^{1)}$, A. G. Reks ${ }^{1)}$, S. V. Klimovich ${ }^{1)}$, O. Yu. Volkova ${ }^{2)}$ \\ ${ }^{1)}$ Belarusian National Technical University (Minsk, Republic of Belarus), \\ ${ }^{2}$ University of Nice - Sophia Antipolis (Nice, France)
}

(C) Белорусский национальный технический университет, 2016

Belarusian National Technical University, 2016

\begin{abstract}
Magnetic fluid is a colloid of magnetic nanoparticles. Using of magnetic fluids in technical devices demands applying of strong non-uniform magnetic fields for a long time. One of the most widespread magnetic fluid devices are magnetic fluid seals of mobile shafts, magnetic fluid supports, bearings, acceleration and angle of inclination gauges, devices for information input in the computer and etc. These devices demand high quality of used fluids. Processes of magnetophoresis and Brownian diffusion in magnetic fluid lead to concentration of magnetic particles in the areas with higher intensity of magnetic field and increase of fluid magnetization in these areas. A local change of particles concentration in the fluid leads to variation of its physical properties. Formation of aggregates from the particles and the further stratification of magnetic fluid, up to its destruction, may be the most serious consequence of redistribution of concentration of magnetic particles. These factors lead to variation of parameters of magnetic fluid devices; cause disturbance of their normal operation and even failure. Therefore, the consistent, high quality magnetic fluids which are not subject to fast stratification in a non-uniform magnetic field are necessary for effective work of the devices. The procedure of evaluation test of quality of magnetic fluids is proposed in this paper. The test is based on studying of influence of processes of magnetophoresis and Brownian diffusion of magnetic particles in magnetic fluid on the forces acting on the volume of fluid in an external non-uniform magnetic field. The procedure is developed on the basis of analysis of magnetic force variation in time under the action of non-uniform field of permanent magnets. Methods of determination of stability of magnetic fluid, known at present, demand rather complicated equipment and laborious and complex investigations. Proposed procedure can be used as an express method for evaluation of magnetic fluid quality for usage in technical devices, and it does not need complicated equipment.
\end{abstract}

Keywords: magnetic fluid, magnetic fluid device, magnetophoresis, Brownian diffusion, quality of magnetic fluids, stability of magnetic fluids

For citation: Bashtovoi V. G., Reks A. G., Klimovich S. V., Volkova O. Yu. (2016) To Evaluation Test of Quality of Magnetic Fluids for Magnetofluid Devices. Energetika. Proc. CIS Higher Educ. Inst. and Power Eng. Assoc. 59 (6), 582-590 (in Russian)

\begin{tabular}{ll}
\hline Адрес для переписки & Address for correspondence \\
Баштовой Виктор Григорьевич & Bashtovoi Viktor G. \\
Белорусский национальный технический университет & Belarusian National Technical University \\
просп. Независимости, 65, & 65 Nezavisimosty Ave., \\
220013, г. Минск, Республика Беларусь & 220013, Minsk, Republic of Belarus \\
Тел.: +375 17 293-96-24 & Tel.: +375 17 293-96-24 \\
unesco@bntu.by & unesco@bntu.by \\
\hline
\end{tabular}




\title{
К оценке качества магнитных жидкостей для магнитожидкостных устройств
}

\author{
В. Г. Баштовой(1), А. Г. Рекс ${ }^{1)}$, С. В. Климович ${ }^{1)}$, О. Ю. Волкова ${ }^{2)}$ \\ ${ }^{1)}$ Белорусский национальный технический университет (Минск, Республика Беларусь), \\ ${ }^{2)}$ Университет Ниццы - Софии Антиполис (Ницца, Франция)
}

Реферат. Магнитная жидкость представляет собой коллоид наночастиц магнетита. Применение магнитных жидкостей в технических устройствах имеет особенность, связанную с необходимостью использования сильно неоднородных магнитных полей в течение длительного промежутка времени. Одними из наиболее распространенных магнитожидкостных устройств являются магнитожидкостные уплотнения подвижных валов, магнитожидкостные опоры, подшипники, датчики ускорения, угла наклона, устройства для ввода информации в ЭВМ и т. п. Данные устройства предъявляют высокие требования к качеству используемых жидкостей. При воздействии неоднородных магнитных полей в магнитной жидкости происходят процессы магнитофореза и броуновской диффузии, что приводит к концентрации магнитных частиц в областях магнитной жидкости с большей напряженностью магнитного поля и увеличению намагниченности жидкости в данных областях. Локальное изменение концентрации частиц в жидкости изменяет ее физические свойства. Наиболее серьезным следствием переконцентрации магнитных частиц может быть образование агрегатов из частиц и дальнейшее расслоение магнитной жидкости вплоть до ее разрушения. Эти факторы приводят к изменению параметров магнитожидкостных устройств, нарушению их работоспособности и даже выходу из строя. Поэтому для их эффективной работы необходимы устойчивые, качественные магнитные жидкости, не подверженные быстрому расслоению в неоднородном магнитном поле. В данной работе предлагается методика оценки качества магнитных жидкостей, основанная на изучении влияния процессов магнитофореза и диффузии броуновских магнитных частиц в магнитной жидкости на силы, действующие в объеме жидкости во внешнем неоднородном магнитном поле. Методика создана на основе анализа характеристик изменения магнитной силы во времени в неоднородном поле постоянных магнитов. Известные в настоящее время методы определения устойчивости магнитной жидкости требуют достаточно сложного аппаратурного оформления и трудоемкой процедуры выполнения комплекса исследований. Предлагаемая методика может быть использована в качестве экспресс-метода оценки качества магнитной жидкости для ее применения в технических устройствах, и она не требует сложной аппаратуры.

Ключевые слова: магнитная жидкость, магнитожидкостное устройство, магнитофорез, броуновская диффузия, качество магнитных жидкостей, устойчивость магнитных жидкостей

Для цитирования: К оценке качества магнитных жидкостей для магнитожидкостных устройств / В. Г. Баштовой [и др.] // Энергетика. Изв. высш. учеб. заведений и энерг. объединений СНГ. 2016. Т. 59, № 6. С. 582-590

\section{Introduction}

Appearance of magnetic fluids which uniquely combine fluidity and strong magnetic properties, has led to creation of new magnetic fluid devices which now are widely used in various branches of industry, especially in power, mechanical engineering, instrument-making, electronics, and vacuum techniques [1-4]. Peculiarity of application of magnetic fluids in technical devices is connected with necessity of use of strong non-uniform magnetic fields during a long time. Therefore, magnetic fluids must be of high quality. Magnetic fluids are colloid of high-dispersed magnetic particles. Therefore, processes of magne- 
tophoresis and diffusion of particles in volume of the fluid lead to redistribution of their concentration under the action of magnetic field $[5,6]$. When magnetic fluid is of poor quality due to many magnetic particles of big size (more than 15 nanometers) and magnetic particles are stabilized badly by surfactant the formation of large aggregates and settling of them occur in magnetic fields. This leads to fluid destruction.

One of the most widespread magnetic fluid devices are magnetic fluid seals of mobile shafts [1-3], which make the most rigid demands to the quality of magnetic fluids. To provide shaft sealing at considerable pressure drops, it is necessary to create a considerable force, acting on the volume of magnetic fluid in the sealed gap. For this purpose creation of strongly non-uniform magnetic field with a gradient of intensity to $10^{9} \mathrm{~A} / \mathrm{m}^{2}$ is required. However, under the action of non-uniform magnetic field in the volume of magnetic fluid, the processes of moving of magnetic particles occur actively, which leads to redistribution of their concentration. As a result, forces acting on the magnetic fluid may undergo considerable changes in the course of time and thereby conditions for sealing of the shaft may change.

Magnetic fluid supports [1-3], accelerometers, devices for information input in computers [4] have high requirements for quality of fluids. The principle of work of the given devices is based on floating of inertial bodies in the container filled with magnetic fluid. Position of the inertial body against container walls should be accurately fixed. In case of a poor quality fluid the body position may spontaneously vary because of the change of magnetic force. This disturbs a normal operation of the device.

The purpose of results presented below is to contribute to development of techniques of preliminary estimation of quality of magnetic fluids for their reliable use in different kinds of devices. The methods of determination of magnetic fluid stability, proposed by this time, demand a composite implementation and laborious procedure for carrying out of researches [7-9].

Proposed technique of estimation of magnetic fluids quality is based on studying of influence of magnetophoresis processes and of Brownian diffusions of magnetic particles in magnetic fluid on the forces acting in the volume of the fluid in an external non-uniform magnetic field.

Magnetic fluid is a colloid of magnetic nanoparticles, so there are processes of magnetophoresis and Brownian diffusion in magnetic fluids under the action of non-uniform magnetic fields [5, 10]. Magnetic particles concentrate in the areas of magnetic fluid with higher intensity of magnetic field $H$, and it brings to increase of fluid magnetization $M$ in these areas. In case of nonlinear distribution of magnetic field intensity in the fluid volume, areas form with the maximum gradient of intensity of the magnetic field and the fluid magnetization. Magnetic force acting on the volume of the magnetic fluid is defined by the product of magnetization and the field gradient, and consequently, it grows nonlinearly with time $[10,11]$. Thus, magnetophoresis and Brownian diffusion have an influence on the force drawing the volume of magnetic fluid to the poles of the source of the magnetic field. This force may be named "magnetic weight". 
The scheme of the experimental unit for investigation of the influnce of magnetophoresis and Brownian diffusion on the magnetic force acting on the volume of magnetic fluid is presented in fig. 1.

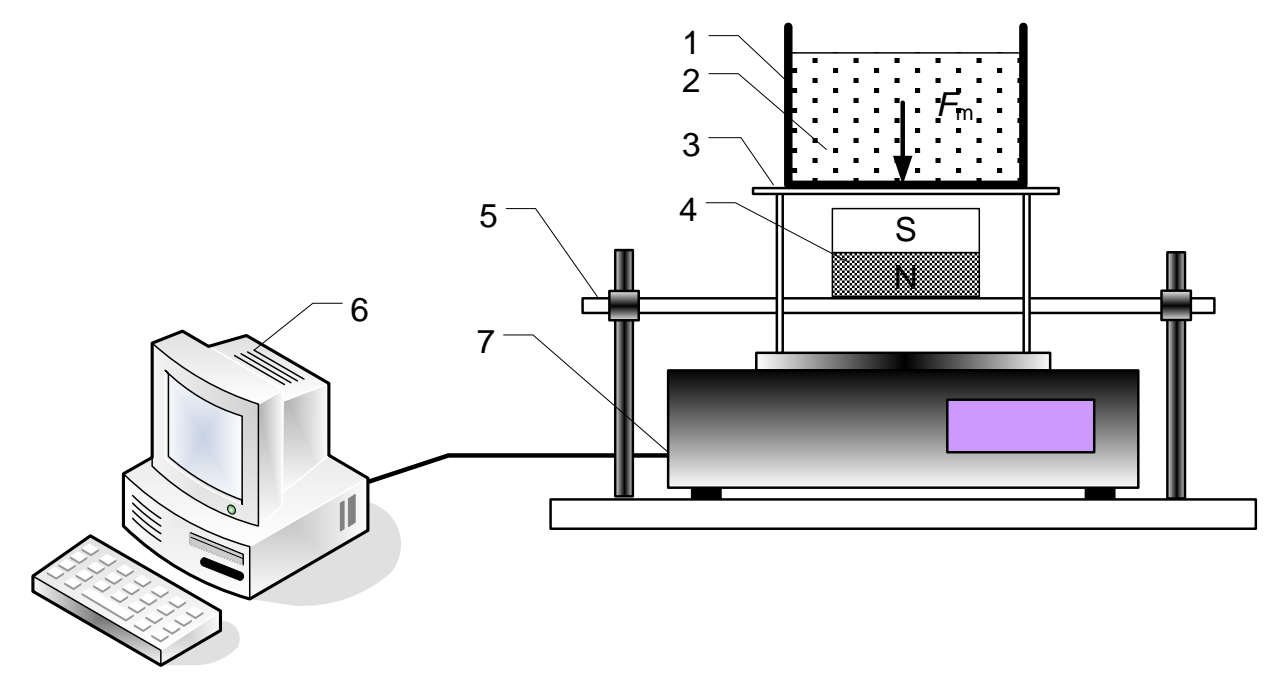

Fig. 1. Scheme of experimental stand

Cuvette 1 from nonmagnetic material, filled with magnetic fluid 2, is placed on nonmagnetic support 3 which is placed on electronic scales 7 . The source of vertically non-uniform magnetic field 4 is placed under the cuvette with the fluid on the other nonmagnetic support 5 .

Since direction of the field gradient is vertical, the magnetic force acting on the volume of magnetic fluid has the vertical direction too, coinciding with a direction of gravity. This fact allows to use scales for measurement of magnetic force. Electronic scales are connected to computer 6 to register the change of magnetic weight of magnetic fluid. In experiments scales OHAUS Adventurer AR2140 are used.

Systems of permanent rectangular ferrite-barium magnets of mark 2BA with the geometrical sizes $10 \times 20 \times 5 \mathrm{~mm}$ are used as a source of vertically nonuniform magnetic field. Magnets, magnetised perpendicularly to the greatest side, are established so that in the volume of magnetic fluid the magnetic field of vertical direction with the gradient of intensity directed vertically downwards is created. Investigation of the vertical distribution of the field of magnets has shown that in the area of the cuvette bottom the maximum intensity $H$ of magnetic field reached the value of $61 \mathrm{kA} / \mathrm{m}$, and gradient of magnetic field intensity is to $12200 \mathrm{kA} / \mathrm{m}^{2}$. At the layer thickness of $10 \mathrm{~mm}$ of magnetic fluid in the field of its blanket, the magnetic field had intensity of $12 \mathrm{kA} / \mathrm{m}$ and gradient of intensity $-1850 \mathrm{kA} / \mathrm{m}^{2}$.

Investigations were carried out with magnetic fluids based on transformer oil. In these fluids, magnetic nanoparticles covered by the surfactant (oleate sodium) acted as a magnetic phase. The basic physical properties of the magnetic fluid samples are presented in tabl. 1. Data concerning the sizes 
of magnetic nanoparticles are received from the analysis of magnetisation curve of magnetic fluids samples [3].

Table 1

Properties of magnetic fluid samples

\begin{tabular}{|l|c|c|c|c|}
\hline \multicolumn{1}{|c|}{ Magnetic fluid } & MOT-20 & MOT-29 & MOT-31 & MOT-39 \\
\hline Magnetization of saturation, kA/m & 19.9 & 29.4 & 31.2 & 38.6 \\
\hline Density $\rho, \mathrm{kg} / \mathrm{m}^{3}$ & 1128 & 1230 & 1274 & 1420 \\
\hline $\begin{array}{l}\text { Volume concentration of magnetic } \\
\text { particles, \% }\end{array}$ & 4.4 & 6.1 & 6.3 & 8.0 \\
\hline Max. diameter of particles, $\mathrm{nm}$ & 13.2 & 10.8 & 11.1 & 11.3 \\
\hline Min. diameter of particles, $\mathrm{nm}$ & 8.6 & 8.4 & 8.4 & 8.1 \\
\hline Dynamic viscosity $\eta, \mathrm{Pa} \cdot \mathrm{s}$ & 0.0344 & 0.0356 & 0.0367 & 0.0797 \\
\hline
\end{tabular}

Intensity of diffusion processes and of Brownian motion in magnetic fluid is described by dimensionless parameter $U=\mu_{0} m_{m} H_{0} / k T$, which represents a relation of magnetic particle energy in magnetic field and its thermal energy [10]. Here $\mu_{0}=1.26 \cdot 10^{-6} \mathrm{G} / \mathrm{m}$ is magnetic permeability of vacuum, $m_{m}$ is magnetic moment of the particle, $k$ is Boltzmann constant, $T$ is absolute temperature.

Due to the change from one to four of the system from the set of constant ferrite-barium magnets in the bottom of the cuvette with magnetic fluid, dimensionless criterium $U$ variated from 2.45 to 6.60 at the performance of experiments.

In a non-uniform magnetic field redistribution of concentration of magnetic particles in magnetic fluids leads, in the course of time, to increase of concentration of magnetic particles near to the cuvette bottom. It causes the growth of magnetic weight $F$ of the fluid in time (fig. 2).

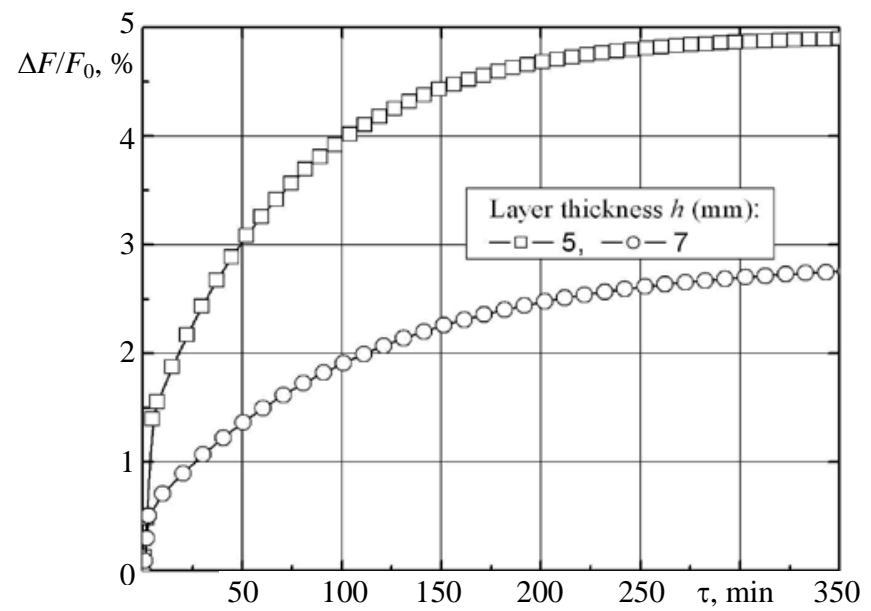

Fig. 2. Time dependence of the relative variation of the magnetic weight of the layers of magnetic fluid MOT-31 of different depth 
In the figure $\Delta F=F-F_{0}$ is absolute variation of magnetic force, $F_{0}$ is magnetic force at the initial moment of activation of magnetic field. This variation occurs the most noticeably at the initial period of time, and further, with the time the fluid weight reaches stationary value and practically does not change. It is stated that the time of reaching the stationary value is from two to three hours, and it corresponds to theoretical estimations [10].

Influence of the diffusion process on magnetic weight variation is more distinct, the more the value of magnetic parameter $U$ is [10]. In fig. 2, dependences for the layers of magnetic fluid of different depth in identical magnetic fields are presented. Average values of parameter $U$ for the layers in depth 5 and $7 \mathrm{~mm}$ are 4.1 and 2.9 respectively. It is visible that for the layer of a smaller depth characterized by a higher value of parameter $U$, a considerably larger variation of acting magnetic force is observed.

According to theoretical estimations variation of magnetic force can reach $10 \%$ due to diffusion [10]. In fig. 3 the dependences characterizing variation of magnetic force acting on magnetic fluid samples in a wide range of magnetization of saturation are presented.

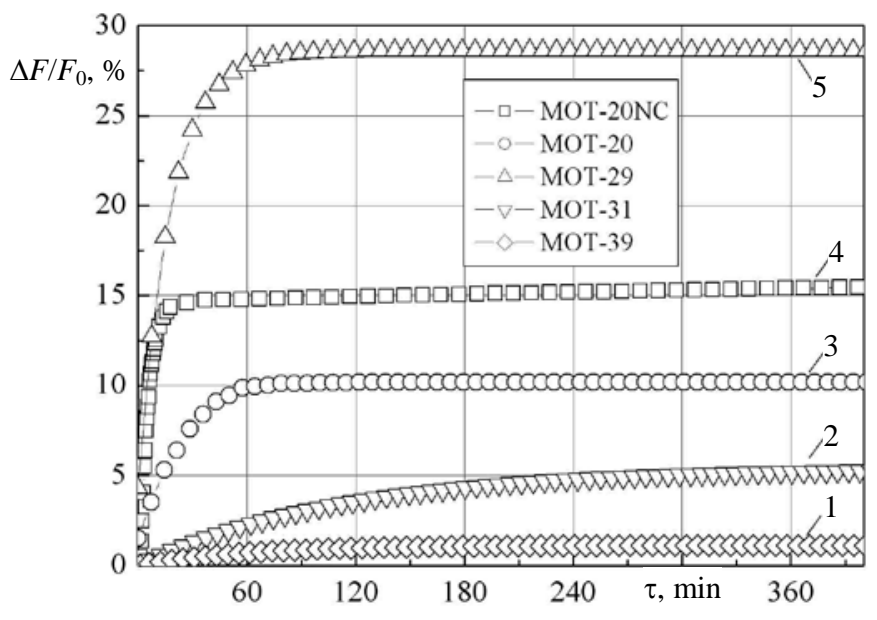

Fig. 3. Time dependence of relative variation of magnetic weight of magnetic fluid samples of different magnetization of saturation

In experiments for all samples of magnetic fluid with stable in time properties a relative change of weight has not exceeded $10 \%$ that is quite accounted for diffusion processes (fig. 3, curves 1-3).

The dependences presented by curves 1-3 are received for magnetic fluids from which for stability increase large magnetic particles and aggregates are removed by centrifugation.

A sample of magnetic fluid MOT-20 was tested in magnetic field twice - before and after centrifugation with acceleration $6000 \mathrm{~g}$. In the sample of fluid before centrifugation (MOT-20NC) a presence of larger magnetic particles and their aggregates is possible. Therefore in a non-uniform magnetic field their fast movement to the area of the stronger magnetic field and sedimentation take 
place. Due to this, a considerable variation of acting magnetic force at the initial moment of time and its coming out to a stationary value (fig. 3, a curve 4) is observed. Subsequently, the given sample of the fluid has appeared steady and has not shown tendency to stratification.

In an hour after switching off the magnetic field the samples of fluid, variation of magnetic weight of which is characterized by dependences 1-3 in fig. 3, have been investigated repeatedly for physical properties (magnetization and density). Tests were taken from the top and the bottom parts of the layer. Their physical properties turned out identical.

Similar investigations have been carried out with a great number of samples of magnetic fluid. It was stated that when magnetic force variation in a non-uniform magnetic field did not exceed $10 \%$, redistribution of concentration of magnetic particles had reversible character, and fluids were characterized by stability of properties. Their use in technical devices did not cause any problems subsequently.

Magnetic fluids of poor quality are characterized by instability of properties because of propensity to sedimentation in gravitational and magnetic fields. Sedimentation may occur in presence of large magnetic particles and at a bad stabilization of magnetic particles by surfactant as well, therefore they cooperate with each other, stick together and form large aggregates. As time goes on, these aggregates drop out in a precipitate. As concentration of magnetic phase in the fluid decreases, then its physical properties change, stratification and even destruction occurs.

Therefore, in magnetic fluid of poor quality in a non-uniform magnetic field, a redistribution of particles concentration and fluid stratification take place more intensively, which leads to stronger increase in time of magnetic weight of the fluid in comparison with better quality fluids. Such considerable change of force is well illustrated by fig. 3 , where comparative dependences of relative variation of weight in time for a set of qualitative magnetic fluids (MOT-39, curve 1; MOT-31, curve 2 and MOT-20, curve 3) and for a poor quality fluid MOT-29 (curve 5) are presented.

It is necessary to notice that in poor quality fluids there is an irreversible redistribution of concentration of magnetic particles in a non-uniform magnetic field. Results of investigation of magnetic properties of different layers of magnetic fluid sample MOT-29 testify to it after its exposure within eight hours in a non-uniform magnetic field. For this purpose sampling of magnetic fluid in the beginning and in the end of the experiment from the surface and the bottom layers was made and their magnetic properties were measured. The received results of investigations are given in tabl. 2.

In the bottom layer of magnetic fluid which is in the area of a stronger field, there is an increase of magnetic particles concentration, in the result of which the magnetic susceptibility of the fluid and magnetization of saturation grow. Visual observation of the fluid sample, taken from the bottom of the cuvette, showed paste like condition. By this, loosing force of magnetic properties of the fluid top layer is observed. Before the experiment the fluid had magnetization of satura- 
tion of $29.4 \mathrm{kA} / \mathrm{m}$, after being in a non-uniform magnetic field magnetization of saturation of the top and the bottom layers became 32.6 and $21.0 \mathrm{kA} / \mathrm{m}$ respectively.

Table 2

Physical properties of magnetic fluid MOT-29 before and after magnetic field acting

\begin{tabular}{|l|c|c|c|}
\hline \multirow{2}{*}{ Parameters } & \multirow{2}{*}{$\begin{array}{c}\text { Initial fluid } \\
\text { MOT-29 }\end{array}$} & \multicolumn{2}{c|}{$\begin{array}{c}\text { Fluid MOT-29 after acting } \\
\text { of the fluid }\end{array}$} \\
\cline { 3 - 4 } & & Surface layer & Bottom layer \\
\hline Magnetization of saturation, KA/m & 29.4 & 21.0 & 32.6 \\
\hline Magnetic concentration of particles, \% & 6.13 & 4.38 & 6.79 \\
\hline Initial magnetic susceptibility & 1.0 & 0.6 & 1.4 \\
\hline
\end{tabular}

The estimation of granulate structure of the given sample of fluid in magnetization curve has shown that the bottom layers of the fluid are characterized by larger sizes of magnetic particles.

The quality (stability) of the fluid samples may be illustrated by the impregnation and drying of the magnetic fluid drop on a filter paper. It is shown in fig. 4.

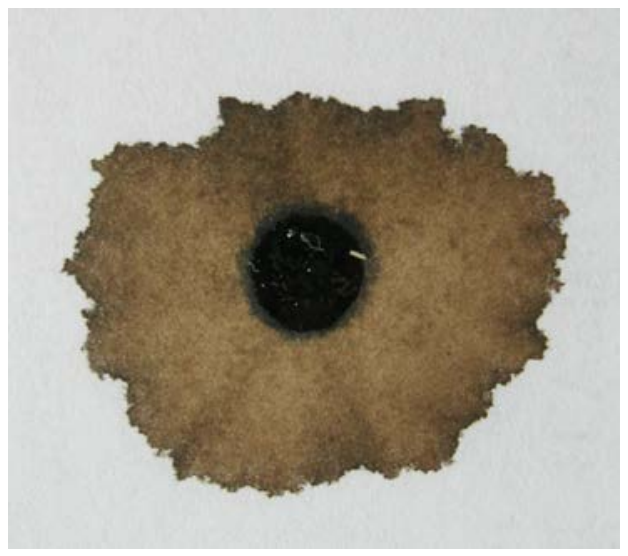

$\mathrm{b}$

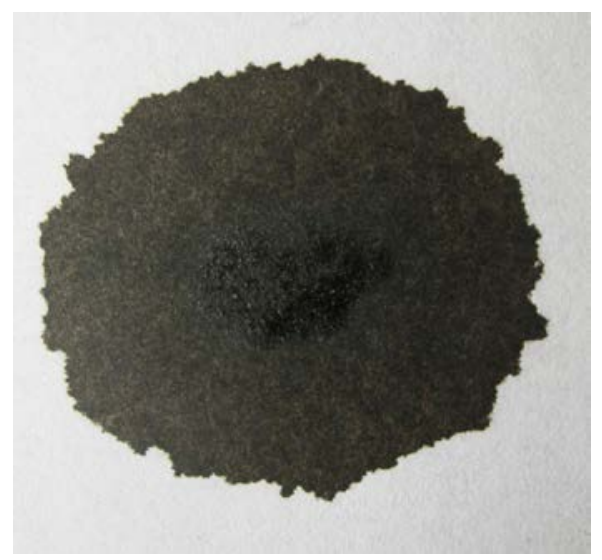

Fig. 4. Photos of the dried drops of the poor quality magnetic fluid and the qualitative one:

$$
\text { a - MOT-29; b - MOT-39 }
$$

In fig. 4 photos of drops of the sample of poor quality magnetic fluid MOT-29 and the sample of high quality MOT-39 are presented for comparison. At drying point, less stable (poor quality) fluid where processes of redistribution of particles concentration occur much more intensively, a stratification and sedimentation of particles in the central part of the drop takes place. By this, the fluid-carrier continues to impregnate the paper. As a result, round the "knob" of magnetite particles the halo of the fluid-carrier is formed (fig. 4a). Stable, qualitative fluid MOT-39 dries uniformly on the occupied area of the paper and forms a homogenous spot that is well visible in fig. $4 \mathrm{~b}$. 


\section{CONCLUSIONS}

1. The fulfilled investigations have shown that under the influence of a nonuniform magnetic field of constant magnets the processes of diffusion and Brownian motion in magnetic fluid occur actively, which influences the magnetic force acting on the volume of magnetic fluid.

2. The analysis of characteristics of magnetic force variation in time may lay down in the basis of the technique of an operative estimation of quality of magnetic fluid.

3. The proposed method can be used as an express method for estimation of quality and stability of magnetic fluid for its use in technical devices and it does not demand composite equipment.

The work is carried out under support of Belarusian Republican Foundation for Fundamental Research.

It is presented by the UNESCO Chair "Energy conservation and renewable Energies".

\section{REFERENCES}

1. Berkovsky B., Bashtovoi V. (Ed.) (1996) Magnetic Fluids and Applications Handbook. New York, Begell House Inc. Publishers. 851.

2. Rosensweig R. E. (1985) Ferrohydrodynamics. USA: Cambridge University Press. 344.

3. Berkovsky B. M., Medvedev V. F., Krakov M. S. (1989) Magnetic Fluids. Moscow, Chemistry. 240 (in Russian).

4. Suprun A., Romanov Yu., Simonenko D. (2001) Device for Inputting Information into the Computer. Patent No 2168201 Russian Federation (in Russian).

5. Landau L. D., Lifshitz E. M. (1986) Theoretical Physics. Vol. VI: Gidrodinamika. Moscow, Science. 736 (in Russian).

6. Bashtovoi V. G., Berkovsky B. M., Vislovich A. N. (1985) Introduction to Thermomechanics Magnetic Fluids. Moscow: IVTAN USSR. 188 (in Russian).

7. Kaiser R., Miskolczy G. (1970) Magnetic Properties of Stable Dispersions of Subdomain Magnetite Particles. Journal of Applied Physics, 41 (3), 1064-1072. DOI: 10.1063/1.1658812.

8. Mikhalev Y. O., Evsin S. I. (1991) Diagnostic Methods of Magnetic Fluids for Sealing Devices. Magnetohydrodynamics, 27 (1), 29-35.

9. Mikhalev Y. O., Novikov S. I., Orlov D. V., Trofimenko M. I. (1982) The Process of Determining the Stability of Magnetic Colloids. Copyright Certificate USSR No 922586.

10. Bashtovoi V. G., Polevikov V. K., Suprun A. E., Stroots A. V., Beresnev S. A. (2007). Influence of Brownian Diffusion on the Statics of Magnetic Fluid. Magnetohydrodynamics, 43 (1), 17-25.

11. Bashtovoi V. G., Reks F. G., Klimovich S. V. (2014) Experimental Research of Magnetophoresis and Brownian Diffusion Influence on "Magnetic Weight” of Magnetic Fluid. Energetika. Izvestiya Vysshikh Uchebnykh Zavedenii i Energeticheskikh Obedinenii SNG [Energetika. Proceedings of CIS Higher Education Institutions and Power Engineering Associations], (1), 65-69 (in Russian).

Received: 19 January 2016 Accepted: 22 Mart 2016 Published online: 29 November 2016 